BLS 35, No 1 2009. DOI: http://dx.doi.org/10.3765/bls.v35i1.3624

(published by the Berkeley Linguistics Society and the Linguistic Society of America)

\title{
The Effects of Coda Voicing on the Onsets of L2 Learners
}

\author{
GWANHI YUN \\ Daegu University
}

\section{Introduction}

It has been well-established that syllables define a domain for phonetic as well as phonological processes. In particular, this paper focuses on the interaction of segments at a sub-phonemic level within a unit of syllable. Classifying subphonemic and phonemic assimilation, Jones (1932) called the former "similitude" rather than assimilation or coarticulation. For instance, when it comes to production, the consonants and vowels within the same syllable have been found to show greater degrees of active coarticulation than across the syllables (Browman and Goldstein 1989). In addition, as for perception, Mehler et al.'s (1981) experiment with French data indicated that "...the syllable constitutes a unit of speech processing and could serve as accessing units to the lexicon..."

Given that syllables consist of onset, nucleus, and coda, within-syllable interaction at the allophonic level is observed in the following types: within-onset, within-coda, onset-nucleus, nucleus-coda, and onset-coda. First, a well-known example of similitude within onsets is partial devoicing of approximants as an influence of preceding voiceless stops (e.g. [pliz] 'please', [twars] 'twice'; Ladefoged 2006). Next, within coda positions, the closure of the first stop is not released until the second stop is closed in a sequence of a stop and a stop consonant as is illustrated in abrupt, exempt, inept... (Hardcastle and Roach 1979). Furthermore, many cases of coarticulation between onsets and nucleus have been found primarily in production. Stetson (1951) found a type of nucleus-to-onset anticipatory coarticulation where tongue body was higher preceding / $\mathrm{i} /$ than preceding /a/ (e.g. /ba/ vs. /bi/, /za/ vs. /zi/). As for the effect of coda on nucleus, vowels were found to be longer before voiced than before voiceless obstruents (Raphael 1972). Last, as is well-known, F0 of nucleus vowels is lower next to voiced than next to voiceless codas (Kingston and Diehl 1994). Such findings allow us to suggest that such a coda-dependent effect might extend to F0 of onsets.

The last type involves long-distance "co-acoustical" effects between onsets and codas. Nguyen and Hawkins $(1998,1999)$ and Hawkins and Nguyen (2003, 2004) suggested that phonetic correlates of codas can be predicted by onsets. What they found was that duration of onset /// and F2 frequency caused listeners 
Gwanhi Yun

to predict voicing of codas. Their perception experiments showed that the longer duration and the lower F2 of /1/ was perceived as real words with voiced codas faster than the shorter and the higher F2 of /1/, leading to an implication that acoustic cues distributed across the syllable play an essential role in word recognition. Hawkins and Nguyen's acoustic studies with 4 speakers of British English also revealed that "...// in onset was $4 \mathrm{~ms}$ longer and showed lower F2 before voiced (e.g. blob) than voiceless codas (e.g. blop)..." (Nguyen and Hawkins 1999:647; see also Nguyen and Hawkins 1998, Hawkins and Nguyen 2003). In addition to $/ 1 /$ in onset, fricatives as well as other sonorants in onset position were longer before voiced than before voiceless codas.

Following Hawkins and Nguyen's recent studies for native speakers of British English, the present study aims to see whether similar coda-dependent acoustic effects can be found with English-learning Korean speakers. The examination of possible coda-dependent effects on onset /1/ with L2 learners could provide a better understanding of how L2 learners are sensitive to allophonic cues stretching from coda over nucleus to onsets.

As is commented by Nguyen and Hawkins (1999), some might wonder if longer duration of onset $/ 1 /$ is an anticipatory effect from the nucleus rather than from a voiced coda. However, note that F2 of nucleus / $/$ / was not affected by voicing of codas at least with British English, but F2 of onset /1/ showed codadependent effects, indicating that the voicing effect stretches far from the coda crossing over the nucleus. Assuming such long-distance dependencies between codas and onsets for L1 speakers, the present study examines whether Englishlearning Korean speakers also show long-distance interaction between onsets and codas at phonetic-fine details primarily in L2 production. If significant effects are obtained with speakers of Korean, it might offer a possibility that voicing can be seen as a syllabic feature across different language users.

\section{Goals}

This study focuses on the L2 production at phonetic-fine details and addresses two questions. The first is whether Korean L2 adult learners' production reflects coda-voicing cues in the onsets in English. If they show the signs of being sensitive to "long-distance" coda dependent effects on onset, it might support the idea that even non-native speakers gradually acquire phonetic fine details such as coarticulation just as L1 speakers do (Oh 2008). Of course, degrees of codadependent effects as compared to effects found in native speakers' production would be utilized to evaluate the proficiency of L2 learners. Second, this study investigates whether voicing is a segment-internal feature or a syllable feature across different language users. Even though voicing is not a contrastive feature for the Korean consonant system, if Korean learners reveal sensitivity to voicing contrasts of codas realized in the acoustic properties of onsets, it might suggest that voicing could be a syllable feature even with L2 learners, depending on L2 learners' exposure to target languages. 


\section{Effects of Coda Voicing on Onsets}

In order to answer these two questions, this present study first aims to see whether voicing effects over the entire syllable can be observed with L2 learners, i.e. speakers of Korean, which does not have a contrast in the voicing of consonants. The second purpose is to see whether L2 learners' syllabic representation includes phonetic-fine details through production if we assume that the production module is linked with the perception module in the mental lexicon.

\section{Acoustic Experiment}

Eight female and two male English-learning native speakers of Korean from Daegu University participated in the current production experiment. All subjects had no known speech disorders in pronunciation. Their major or minor was English. They were all junior or senior college students. All were intermediate or advanced English learners collected on the basis of achieving English-related course records of $80 \%$ out of $100 \%$. One weakness with our experiment is that the subjects learned American English primarily, while the results in this study will be compared with the results with speakers of British English (Hawkins and Nguyen 2004). Participants' ages ranged between 22 and 28 with an average age of 23.1. They had all learned English in school, starting between ages 8 and 14 . The average age of starting English learning was 13.3 years. Their mean period of learning English was 11 years.

Most of the materials were created similarly to the data in Hawkins and Nguyen (2004) in order to easily compare the results with native speakers of British English. All the stimuli were monosyllabic /(C)lVC/ nonce words. Onsets were a single $/ \mathrm{l} /$ or six consonant clusters, including $/ \mathrm{l} /(/ \mathrm{l}, \mathrm{bl}, \mathrm{pl}, \mathrm{gl}, \mathrm{kl}, \mathrm{fl}, \mathrm{sl} /)$, and nuclei varied among eleven vowels $/ \mathrm{i}, \mathrm{I}, \mathrm{e}, \varepsilon, \mathrm{e}$,, aI, a, $\Lambda$, au, u/. Codas consisted of voiced/voiceless stops according to three places of articulation (/b, p, d, t, g, k/). Since this study examines the acoustic characteristics of onset /1/ possibly affected by coda-voicing, /1/ was included in each onset type. Further, onsets were divided into subcategories such as a single $/ 1 /$, a stop followed by $/ 1 /$, and a fricative followed by $/ 1 /$. All these types were legitimate in English onset clusters. A subset of stimuli materials are illustrated in (1).

(1) Stimuli

$/ \mathrm{l}+\mathrm{V}+\mathrm{C} /$

lead leat

lid lit

/bl+V+C/

bleed bleet

blid blit

$/ \mathrm{pl}+\mathrm{V}+\mathrm{C} /$

plead pleet

plid plit

$\begin{array}{llll}\text { leab } & \text { leap } & \text { leak leag } \\ \text { lib lip } & \text { lick } & \text { lig } \\ \text { bleeb } & \text { bleep } & \text { bleak } & \text { bleeg } \\ \text { blib blip } & \text { blik } & \text { blig } \\ & & & \\ \text { pleeb } & \text { pleep } & \text { pleek } & \text { pleeg } \\ \text { plib plip } & \text { plick plig }\end{array}$


Gwanhi Yun

\begin{tabular}{|c|c|c|c|}
\hline gleed gleet & gleeb & gleep & gleek \\
\hline $\begin{array}{l}\text { glid glit } \\
/ \mathrm{k} 1+\mathrm{V}+\mathrm{C} /\end{array}$ & glib & glip & glick \\
\hline kleed kleet & kleeb & kleep & kleek \\
\hline $\begin{array}{l}\text { klid klit } \\
/ \mathrm{fl}+\mathrm{V}+\mathrm{C} /\end{array}$ & klib & clip & click \\
\hline fleed fleet & fleeb & fleep & fleek \\
\hline $\begin{array}{l}\text { flid flit } \\
/ \mathrm{s} 1+\mathrm{V}+\mathrm{C} /\end{array}$ & flib & flip & flick \\
\hline sleed sleet & sleeb & sleep & sleek \\
\hline slid $\quad$ slit & slib & slip & slik \\
\hline
\end{tabular}

In total, 4620 stimuli (7 onset types x 11 nucleus vowels x 6 codas) were collected and analyzed, including 1240 filler words. As is shown above, the words in a minimal pair consisted of the same onset and nucleus vowel except for the voicing contrast. Since this study focused on the coda voicing factor, the acoustic properties of onset /1/ were compared in both conditions.

All the subjects were instructed to read the stimuli list in (2) in random order at a normal speaking rate. Each word was embedded in the carrier sentence Please say to me to minimize the effects of other factors. Their sounds were recorded with PRAAT in the computer in a sound-attenuated phonetics lab. This recording was done digitally. The digitization was done at $44100 \mathrm{~Hz}$ sampling rate. Probably because of the advanced level of English, most speakers had little trouble pronouncing the onset sequences such as ' $\mathrm{Cl}$ ' without inserting vowels between clusters. F2 frequency and F0 of $/ 1 /$ in both the conditions (voiced/voiceless codas) were measured at the midpoint of $/ 1 /$; the duration of $/ 1 /$ was also measured.

\section{Results}

\subsection{Coda-Voicing Effect on $F 2$ of Onset ///}

Table 1 shows the mean and standard deviation of F2 in onset /1/ in voiced and voiceless coda conditions.

Table 1. The mean and standard deviation of $F 2$ in onset $/ \mathrm{l} /$ in voiced/voiceless conditions

\begin{tabular}{cccccc}
\hline \hline & & Mean & N & SD & SE \\
\hline \hline F2 $(\mathrm{Hz})$ & voiceless & 1488 & 70 & 209 & 24 \\
& voiced & 1479 & 70 & 216 & 25 \\
\hline
\end{tabular}

A paired-sample t-test revealed that there was no significant difference in F2 frequency of onset $/ 1 /$ between the voiced and voiceless coda conditions ( $1488 \mathrm{~Hz}$ vs. $1479 \mathrm{~Hz} ; t(69)=1.0, \mathrm{p}>0.05)$. It indicates that overall, the coda voicing factor did not exert influence on the F2 of onset /1/ with Korean speakers. This finding 


\section{Effects of Coda Voicing on Onsets}

differs from that with native speakers of English, i.e., F2 of onset /1/ was lower before voiced than voiceless codas (Nguyen and Hawkins 1998).

Then we looked into coda-dependent effects on the F2 patterns in onset /1/ for individual speakers. A paired-sample t-test revealed that there was a highly significant difference in F2 for two speakers i.e. a female speaker K6 and a male speaker $\mathrm{K} 8(t(223)=3.11, \mathrm{p}<0.001$ for $\mathrm{K} 6$; $t(225)=3.08, \mathrm{p}<0.01)$. That is, interestingly, F2s of onset /1/ were lower before voiced than before voiceless codas for at most two speakers. This result indicates that for F2 values of onset /1/, coda-dependent effects on the onset varied from speaker to speaker. The upshot is that some L2 learners produced onset /1/ differently, depending on the voicing of codas, like native speakers of English, revealing long-distance anticipatory effect from coda to onset. As Nguyen and Hawkins (1999) comment, the fact that onset /1/ showed lower F2s indicates that /1/ was pronounced slightly darker before voiced codas than before voiced ones.

Table 2 shows the mean and standard deviation of F2 in onset /1/ according to three subcategories of onset type. A post-hoc paired sample t-test revealed that there was a significant difference in the F2 of the onset when the onset was a single $/ 1 /$, but no difference when $* / 1 /$ was included in consonant clusters CC. Like native speakers of English, F2 of onset /1/ was lower before voiced codas than before voiceless ones $(1567 \mathrm{~Hz}$ vs. $1608 \mathrm{~Hz}, t(9)=2.47, \mathrm{p}<0.05)$. This indicates that overall, Korean speakers produced onset /1/ a littler darker before voiced codas than before voiceless codas particularly only when onset was a single $/ 1$, confirming sensitivity to long-distance coda effects on onsets in production.

Table 2. The mean and standard deviation of F2 in onset /l/ in voiced/voiceless conditions by onset types

\begin{tabular}{|c|c|c|c|c|c|}
\hline \multicolumn{2}{|c|}{ Onset Type } & Mean of F2 & $\mathrm{N}$ & $\mathrm{SD}$ & $\mathrm{SE}$ \\
\hline \multirow[t]{2}{*}{ IVC } & vls & 1608 & 10 & 243 & 76 \\
\hline & $\mathrm{vd}$ & 1567 & 10 & 237 & 75 \\
\hline \multirow[t]{2}{*}{$\mathrm{bl}, \mathrm{pl}, \mathrm{gl}, \mathrm{kl}$} $\mathrm{VC}$ & vls & 1449 & 10 & 179 & 56 \\
\hline & $\mathrm{vd}$ & 1441 & 10 & 188 & 59 \\
\hline \multirow[t]{2}{*}{$\mathrm{fl}, \mathrm{sl}$} $\mathrm{VC}$ & vls & 1508 & 10 & 218 & 69 \\
\hline & $\mathrm{vd}$ & 1511 & 10 & 221 & 70 \\
\hline
\end{tabular}

In summary, although the overall results with all speakers did not exhibit significant coda-dependent effects on F2s in onset /1/, some individual speakers showed signs of sensitivity to different voicing of codas. This result is interesting in that L2 learners are partly predicting coda-voicing contrasts, even in the pronunciation of onsets, or that they capture the voicing effects across the whole syllable like native speakers of English.

\subsection{Coda-Voicing Effect on Duration of Onset ///}

Table 3 displays the mean and standard deviation of duration in onset / $1 /$ between voiced and voiceless coda conditions. A paired-sample t-test with all subjects 
Gwanhi Yun

revealed that there was a significant coda-dependent effect on duration of onset $/ 1$, confirming "long-distance coarticulation" effect $(t(69)=-3.778, \mathrm{p}=0.001)$. Duration of onset /1/ was $5 \mathrm{~ms}$ longer before voiced than before voiceless codas (86 ms vs. $81 \mathrm{~ms}$ ). This finding totally agrees with the result with native speakers of English (Nguyen and Hawkins 1999), indicating that, interestingly, Korean L2 learners are acquiring native-like sub-phonemic assimilation.

Table 3. The mean and standard deviation of duration of onset /// in voiced/voiceless conditions

\begin{tabular}{cccccc}
\hline & & Mean of length $(\mathrm{ms})$ & $\mathrm{N}$ & $\mathrm{SD}$ & $\mathrm{SE}$ \\
\hline Duration of $/ \mathrm{l} /$ & voiceless & 81 & 70 & 29 & 3.4 \\
& voiced & 86 & 70 & 32 & 3.9 \\
\hline
\end{tabular}

Table 4 exhibits the mean and standard deviation of duration in onset $/ 1 /$ in voiced and voiceless coda conditions, depending on three onset types. A pairedsample t-test within each onset type revealed that there was a significant codavoicing dependent effect on the duration of onset $/ 1 /$ when the onset cluster CC was 'a stop $+/ 1 /$ ' (e.g. blid vs. blit) or 'a fricative $+/ 1 /$ ' (e.g. flid vs. flit) $(t(9)=-$ 2.194, $\mathrm{p}=0.05$ for 'a stop $+/ 1 /$ '; $t(9)=-2.91, \mathrm{p}<0.05$ for 'a fricative $+/ 1 /$ ' $)$. As is seen in Table 4, onset /1/ was $6 \mathrm{~ms}$ longer before voiced than before voiceless codas when onset clusters consisted of a stop followed by /1/ ( $80 \mathrm{~ms}$ vs. $74 \mathrm{~ms})$. Similarly, the duration of onset /1/ was $6 \mathrm{~ms}$ longer before voiced than before voiceless codas when the onset clusters were a fricative followed by /1/ ( $84 \mathrm{~ms}$ vs. $78 \mathrm{~ms}$ ). As was mentioned in previous section, though most of the CC onset clusters were pronounced without an inserted vowel by advanced learners, the length difference squarely reflects the coda-dependent effects on the onset /1/ rather than the duration of complex onsets. However, there was no significant coda-voicing effect on the duration of onset $/ 1 /$ when the onset was a single $/ 1 /$ ( $t$ (9) $=0.02, p>0.05)$.

Table 4. The mean and standard deviation of duration of onset /l/ according to onset type

\begin{tabular}{|c|c|c|c|c|c|}
\hline \multicolumn{2}{|l|}{ Onset Type } & Mean of length (ms) & $\mathrm{N}$ & SD & SE \\
\hline \multirow[t]{2}{*}{ IVC } & vls & 114 & 10 & 20 & 6.5 \\
\hline & $\mathrm{vd}$ & 114 & 10 & 23 & 7.3 \\
\hline \multirow[t]{2}{*}{$\mathrm{bl}, \mathrm{pl}, \mathrm{gl}, \mathrm{kl}$} $\mathrm{VC}$ & vls & 74 & 10 & 24 & 7.7 \\
\hline & $\mathrm{vd}$ & 80 & 10 & 29 & 9.3 \\
\hline \multirow[t]{2}{*}{$\mathrm{fl}, \mathrm{sl}$} $\mathrm{VC}$ & vls & 78 & 10 & 25 & 8.1 \\
\hline & $\mathrm{vd}$ & 84 & 10 & 28 & 8.9 \\
\hline
\end{tabular}

In brief, this result suggests that Korean L2 learners are sensitive to coda-voicing contrasts in the pronunciation of onset /1/, specifically when $/ 1 /$ is part of complex onsets. Further, this finding provides the interesting implication that even for 


\section{Effects of Coda Voicing on Onsets}

English-learning Korean speakers, syllables can be specified as having voiced or voiceless codas even from the beginning of onsets, like native speakers of English (Nguyen and Hawkins 1998, 1999).

A one-way ANOVA with a factor of three types of onsets showed that there was a significant effect of onset-type on duration of onset $/ 1 /(F(2,57)=13.46$, $\mathrm{p}<0.001)$. When coda-voicing collapsed, a single onset $/ \mathrm{l} / \mathrm{was}$ the longest (114 $\mathrm{ms})$, the duration of onset /l/ following a fricative (/fl, sl/) was next longest (81 $\mathrm{ms}$ ), and onset /l/ following a stop (/bl, pl, gl, kl/) was the shortest (77 ms).

Next, Figure 1 displays the mean duration of onset /1/ in both voiced and voiceless coda conditions according to seven onset types (/l, bl, $\mathrm{pl}, \mathrm{gl}, \mathrm{kl}, \mathrm{fl}, \mathrm{sl} /$ ). A post-hoc paired-sample t-test was conducted to see coda-dependent voicing effects on the duration of onset / $1 /$ according to each of seven onset types. The analysis revealed that there was a significant coda-voicing effect on the duration of onset $/ 1 /$ for $/ \mathrm{kl} /$ and $/ \mathrm{sl} /$ onset clusters (for $/ \mathrm{kl} /, t(9)=-2.436, \mathrm{p}<0.05$; for $/ \mathrm{sl} /, t$ $(9)=-2.9, p<0.05)$. Specifically, onset $/ 1 /$ was longer before voiced than before voiceless codas when onset clusters were /bl, kl, sl/ (for /bl/, $96 \mathrm{~ms}$ vs. $84 \mathrm{~ms}$; for /kl/, $67 \mathrm{~ms}$ vs. $61 \mathrm{~ms}$; for/sl/, $95 \mathrm{~ms}$ vs. $87 \mathrm{~ms}$ ).

Figure 1. The mean of duration of onset $/ \mathbf{l} /$ for seven onset types in voiced/voiceless coda condition ${ }^{1}$

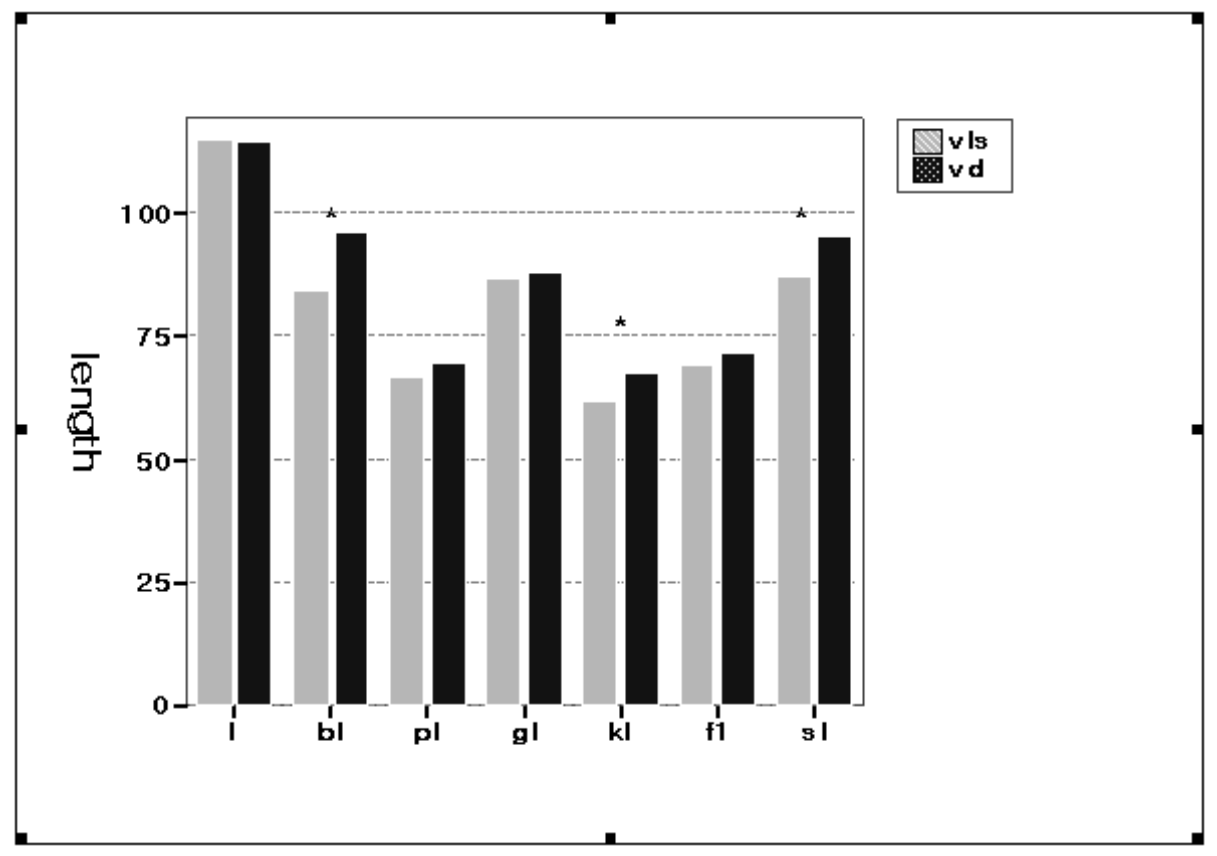

Let us turn to coda-voicing effect on duration of onset / $1 /$ according to nucleus vowel types. A post-hoc paired-sample t-test was conducted. The analysis revealed that there were significant effects of coda-voicing on duration of onset /1/ primarily

\footnotetext{
$1 *$ represents significant differences
} 
Gwanhi Yun

when the nucleus vowels were front mid vowels /i, I/, but as for /e, $\varepsilon /$, coda-voicing showed insignificant tendency. Duration of onset / $1 /$ was longer before voiced than before voiceless codas when $\mathrm{V}$ in a sequence of (C)lVC was /i, I, e, $\varepsilon$ / (for /i/, $91 \mathrm{~ms}$ vs. $81 \mathrm{~ms}, t(9)=-4.248, \mathrm{p}<0.01$; for $/ \mathrm{I} /, 85 \mathrm{~ms}$ vs. $79 \mathrm{~ms}, t(9)=-2.34, \mathrm{p}<0.05$; for /e/, $90 \mathrm{~ms}$ vs. $76 \mathrm{~ms}, t(9)=-2.076, \mathrm{p}=0.06$; for $/ \varepsilon /, 84 \mathrm{~ms}$ vs. $77 \mathrm{~ms}, t(9)=-1.926$, $\mathrm{p}=0.08$ ). This result indicates that Korean L2 learners might have predicted coda voicing before the start of codas by producing onset /1/ longer before voiced than before voiceless codas, showing native-like patterns of phonetic fine details such as "long-distance" interaction within syllables.

In summary, we found that, overall, onset /1/ was significantly and slightly longer before voiced than before voiceless codas with Korean L2 learners, confirming long-distance anticipatory effects of coda-voicing on the onsets. These robust anticipatory effects are consistent with the results with native speakers of English, suggesting L2 learners' native-like sensitivity to voicing effects across whole syllables.

\subsection{Coda-Voicing Effect on F0 of Onset ///}

Previous studies found that F0 of onset /1/ did not exhibit coda-voicing dependent effects on onsets with native speakers of English (Nguyen and Hawkins 1998, Hawkins and Nguyen 2004). Native speakers of English did not turn on the signal of F0 in onsets to indicate anticipatory coda-voicing. In order to directly compare such findings with Korean L2 learners' production, F0 at the midpoint of onset /1/ was measured. Table 5 displays the mean and standard deviation of F0 in onset /1/ in both conditions. Interestingly, a paired-sample t-test revealed that there was a highly significant effect of coda-voicing on F0 in onset $/ 1 /(t(55)=3.906$, $\mathrm{p}<0.001)$. Unlike the case of native speakers of English, F0 of onset /1/ was lower before voiced than before voiceless codas $(204 \mathrm{~Hz}$ vs. $207 \mathrm{~Hz})$. What is of interest here is that Korean L2 learners employed more than one supra-segmental acoustic cue such as F0 as well as duration in onset /1/ to indicate voicing contrast in coda.

Table 5. The mean and standard deviation of F0 of onset /l/ in voiceless/voiced conditions

\begin{tabular}{lcccc}
\hline & Mean F0 $(\mathrm{Hz})$ & $\mathrm{N}$ & $\mathrm{SD}$ & $\mathrm{SE}$ \\
\hline Vls & 207 & 56 & 45.2 & 6.0 \\
Vd & 204 & 56 & 44.5 & 5.9 \\
\hline
\end{tabular}

This result implies that even L2 speakers of Korean might have lexical representation with voicing feature stretching over the whole syllable.

A post-hoc one-way within-subject ANOVA with one factor (onset-type: /1/ vs. /bl, $\mathrm{pl}, \mathrm{kl} / \mathrm{vs}$. /fl, sl/) was conducted to see if there is a coda-voicing effect on F0 in onset $/ 1 /$. Analysis revealed that overall, there was no significant effect $(F(2,45)$ $=1.354, \mathrm{p}>0.05)$. However, a paired-sample t-test within each onset type displayed that there was a significant effect of coda-voicing on F0 in onset /1/ when onset / $/$ was followed by stops $/ \mathrm{b}, \mathrm{p}, \mathrm{g}, \mathrm{k} /(t(7)=2.392, \mathrm{p}<0.05)$. It was found that 


\section{Effects of Coda Voicing on Onsets}

F0 of onset /1/ was slightly but significantly lower before voiced than before voiceless codas in the onset type /bl, pl, gl, kl/ as is illustrated in Figure 7 (205 Hz vs. $207 \mathrm{~Hz}$ ).

In summary, overall this investigation of F0 in onset /1/ revealed that Korean L2 learner's production of onsets were sensitive to predicting voicing contrast in codas, unlike native speakers of English, i) when onset clusters consisted of a stop followed by /1/ and ii) when coda consonants were coronals and labials. Thus this finding confirms "long-distance" influences of codas on onsets with L2 learners" production. More detailed implications on the acquisition of phonetic fine details by Korean L2 learners and the phonological status of voicing will be discussed in the following section.

\section{Discussion}

This study examined acoustic characteristics of onset /1/ to see if they are affected across nucleus vowels by the voicing feature of codas, especially with Englishlearning Korean speakers. We address two issues: (i) the availability of phonetic fine details such as duration, F0, and F2 that L2 learners might adopt to predict codavoicing, and (ii) the possibility of specifying a voicing feature as spreading over the whole syllable in their mental representations.

First, as for the availability of phonetic fine details to predict long-distance influence by codas, results based on production of onset /1/ by ten English-learning speakers of Korean showed coda-voicing dependent effects on the onset. However, they were more sensitive to duration and F0 of /1/ than F2 of /1/ in onset. Such results slightly differ from a series of Hawkins and Nguyen's consistent studies in that native speakers of English exhibited significant effects with respect to F2 and duration of onset $/ 1 /$, while F0 of onset /1/ was not affected. When it comes to Korean L2 learners, F2 of onset /1/ was lower before voiced than voiceless codas only i) for two speakers out of ten and ii) when codas were coronals. But overall duration of onset $/ 1 /$ was longer before voiced than before voiceless codas. In addition, F0 of onset /1/ was lower before voiced than before voiceless codas. Put together, interestingly, Korean L2 learners mobilized more acoustic cues in the production of onset /1/ to predict coda-voicing than native speakers of English.

Thus, it is worthwhile to tackle the question of why Korean L2 learners resort to duration and F0 more than F2 in onsets. Put differently, supra-segmental elements like duration and F0 are more available than a lingual element like F2 involving tongue back position. One possible explanation involves phonological or phonetic transfer from Korean. As is reported in the present study, Korean L2 learners showed slightly "darker" /1/ by producing onset /1/ with lower F2 before voiced than before voiceless codas only with two speakers out of ten. This finding in a relatively small number of subjects implies that they might not yet have acquired subtle subphonemic details in the production of $/ 1 /$. Such difficulty in production of phonetic fine details or acquisition of F2 might be due to the fact that there is no contrast between clear [1] and dark [1] at sub-phonemic level in Korean. However, suprasegmental elements like duration and pitch are relatively more available for the 
Gwanhi Yun

Korean vowel or consonant system in a limited way. Kim's (2002) acoustic study of Korean stops found that closure duration of intervocalic tense and aspirated consonants is more than two times as long as lax consonants, and closure duration is the longest for the tense consonants. Further, it is well-known that a vowel length contrast still exists in a small range of lexical items with two or three syllables in most dialects except for the Seoul standard dialect (Jun 1995). In addition, Kim et al.'s (1993) acoustic and perception study exhibited that F0 in the first five glottal pulses were higher in aspirated and tense stops than in lax stops. Furthermore, F0 played a crucial role as a perceptual cue in the distinction of three-way stops.

These differences in the role of production and perception between F2 and duration and F0 in the Korean phonological/phonetic system might have transferred to the acquisition of phonetic fine details in English. Another line of explanation might involve markedness between duration and F2 across languages. Specifically, supra-segmental cues like length and pitch in vowels and consonants might be less marked than segmental lingual properties like F2, making it easier for L2 learners to acquire and manipulate than formant frequencies of $/ 1 /$. The rationale behind this reasoning is that length and pitch are features commonly used cross-linguistically and thus are more likely to adapt for L2 production. As an anonymous reviewer points out, our results interestingly contrast with Dupoux et al.'s (2008) finding that L2 learners have more trouble learning stress than segments. Despite such differences, the overall results in the present study provide many interesting implications. First, the results show that Korean L2 learners are acquiring coda-voicing effects on the sub-phonemic properties of onset $/ 1 /$ in English even though their availability is not identical. Such findings support Kuhl and Iverson's (1995) position that L2 learners' perceptual flexibility to phonetic properties in target languages (English) influenced their production, depending on their L2 experience or exposure to target languages, given that the production mechanism is closely linked to the perception system in their mental lexicon. Second, this study shows that voicing features of codas spread across syllables even in the production of Korean, with no phonological voicing contrast in its consonant system. Thus it leads us to offer the interesting implication that a voicing feature might be phonetically universal and can be specified as a syllable feature beyond segments.

Second, it was found that a contrast in the voicing of codas was manifested in the phonetic realization of onset /1/ for L2 learners with respect to F0, F2 and duration of $/ 1 /$. As is discussed in the previous section, extension of phonetic correlates of a voicing feature over the entire syllable induces us to speculate that voicing might be a syllable feature rather than a segment-internal feature (Shastri et al. 1999, Greenberg 2004). Such an idea holds in terms of perception or word recognition (Nguyen and Hawkins 1999). That is, longer duration, lower F0, and lower F2 of onset /1/ followed by longer duration of nucleus vowels followed by shorter duration of voiced codas might contribute to enhancing the perception of voicing in the whole syllable or word according to "Auditory Enhancement Theory" (Kingston and Diehl 1994). 


\section{Effects of Coda Voicing on Onsets}

\section{Conclusion}

In this acoustic study, we explored "long-distance" co-acoustical patterns between onset and coda in (C)lVC sequences in English-learning Korean speakers. Results showed that they were sensitive to coda voicing effects on onset /1/ through phonetic fine details like F0, F2, and duration of /1/. Onset /1/ was slightly longer, darker (lower F2), and lower-pitched before voiced than before voiceless codas. This finding supports the position that even L2 learners are able to acquire subphonemic details like native speakers. Furthermore, it provides several interesting implications. First, the voicing property can be a syllable feature, influencing all the segments in the same syllable. Second, more robust phonetic manifestations of durational and F0 effects over F2 might be due to the possibility that the Korean L2 learners are more sensitive to temporal cues than to spectral cues.

Further studies are still worth pursuing to confirm the acoustic results of this investigation. First, it might be interesting to see if the delicate differences in F0, F2 and duration of onset /1/ affect word recognition for English-learning Korean listeners. Prospective significant results will definitely validate the status of voicing as a syllable feature even for L2 learners. Second, we might attempt to find out if other parameters, like the L2 learners' proficiency level, differently affect production and perception of phonetic fine details.

\section{References}

Browman, Catherine, and Louis Goldstein. 1989. Articulatory gestures as phonological units. Phonology 6:201-252.

Dupoux, Emmanuel, Núria Sebastián-Galles, Eduardo Navarrete, and Sharon Peperkamp. 2008. Persistent stress 'deafness': The case of French learners of Spanish. Cognition 106(2):682-706.

Greenberg, Steven. 2004. Beyond landmark-based speech recognition. Paper presented at Johns Hopkins University.

Hardcastle, Williams, and Peter Roach. 1979. An instrumental investigation of coarticulation in stop consonant sequences. In H. Hollien and P. Hollien, eds., Current issues in the phonetic sciences, 531-540. Amsterdam: John Benjamins.

Hawkins, Sarah, and Noël Nguyen. 2003. Effects on word recognition of syllableonset cues to syllable-coda voicing. In John Local, Richard Ogden and Rosalind Temple, eds., Phonetic interpretation: Papers in Laboratory Phonology VI, 38-57. Cambridge: Cambridge University Press.

Hawkins, Sarah, and Noël Nguyen. 2004. Influence of syllable-coda voicing on the acoustic properties of syllable-onset /1/ in English. Journal of Phonetics 32(2):199-231.

Jones, Daniel. 1932. Outline of English phonetics. Cambridge University Press.

Jun, Sun-Ah. 1995. The accentual phrase in the Korean prosodic hierarchy. Phonology 15:189-226. 
Gwanhi Yun

Kim, Hyunsoon. 2002. Closure duration, glottal width, and glottal tension in Korean three-way phonation consonants. Paper presented at the $8^{\text {th }}$ Conference on Laboratory Phonology, Yale University.

Kim, Mi-Ran, Charles Read, Keith Kluender, and Andrew Lotto. 1993. Production and perception of word-initial stops by Korean adults. Journal of the Acoustical Society of America 94(3):1865-1866.

Kingston, John, and Randy L. Diehl. 1994. Phonetic knowledge. Language 70:419-454.

Kuhl, Patricia K., and Paul Iverson. 1995. Linguistic experience and the perceptual magnet effect. In Winifred Strange, ed., Speech perception and linguistic experience, 121-154. Baltimore: York Press.

Ladefoged, Peter. 2006. A course in phonetics. Boston, MA: Thomson/ Wadsworth Publishers.

Mehler, Jacques, Jean-Yves Dommergues, Uli Frauenfelder, and Juan Segui. 1981. The syllable's role in speech segmentation. Journal of Verbal Learning and Verbal Behavior 20:298-305.

Nguyen, Noël, and Sarah Hawkins. 1998. Syllable-onset acoustic properties associated with syllable-coda voicing. Proceedings of the $5^{\text {th }}$ International Conference on Spoken Language Processing. Available on CD-ROM: ICSLP98. Paper \#539.

Nguyen, Noël, and Sarah Hawkins. 1999. Implications for word recognition of phonetic dependencies between syllable onsets and codas. In John J. Ohala, Yoko Hasegawa, Manjari Ohala, Daniel Granville, and Ashlee C. Bailey, eds., Proceedings of the XIVth International Congress of Phonetic Science 647650. San Francisco.

Oh, Eunjin. 2008. Coarticulation in non-native speakers of English and French: An acoustic study. Journal of Phonetics 36(2):361-384.

Raphael, Lawrence. 1972. Preceding vowel duration as a cue to the perception of the voicing characteristic of word-final consonants in American English. Journal of the Acoustical Society of America 51:1296-1303.

Shastri, Lokendra, Shuangyu Chang, and Steven Greenberg. 1999. Syllable detection and segmentation using temporal flow neural networks. In John J. Ohala, Yoko Hasegawa, Manjari Ohala, Daniel Granville, and Ashlee C. Bailey, eds., Proceedings of the XIVth International Congress of Phonetic Sciences 1721-1724. San Francisco.

Stetson, Raymond. 1951. Motor phonetics: A study of speech movements in action ( $2^{\text {nd }}$ ed.). Amsterdam: North Holland.

Department of English Language and Literature

Daegu University

15 Naeli, Jillyang, Gyeongsan, Gyeongbuk

Korea $712-714$

ghyun@daegu.ac.kr 